\title{
Atributos do solo em sistemas diferenciados de uso e manejo do solo em Mato Grosso, MT, Brasil
}

Ana Carla Stieven, Willian Mesquita Mendes, Flavio Wruck, Eduardo Guimarães Couto, Daniela Tiago da Silva Campos

Centro Universitário de Várzea Grande - UNIVAG, MT. Instituto Ambiental Base, MT. EMBRAPA Agrossilvipastoril, Sinop, MT. Universidade Federal de Mato Grosso - UFMT, MT. E-mail: anastieven@yahoo.com.br

\section{Resumo}

Sistemas diferentes de uso do solo têm sido propostos e implementados na região centro-oeste do Brasil. Essas novas técnicas garantem a recuperação de áreas degradadas e a potencialização do uso, e por isso têm se tornado cada vez mais frequentes, o que exige conhecimento técnico para confirmar a sua viabilidade. $\mathrm{O}$ objetivo deste trabalho foi avaliar os atributos químicos e microbiológicos de uma área sobre Latossolo Vermelho-Amarelo Distrófico com três sistemas de integração lavoura-pecuária-floresta e compará-los com uma área de pasto e floresta nativa, em dois anos de avaliação. As coletas foram realizadas em uma unidade de referência tecnológica da Embrapa Agrossilvipastoril, ao norte do estado de Mato Grosso. As análises microbiológicas do solo foram realizadas com o método de fumigação-incubação para a determinação de carbono da biomassa microbiana e seus derivados; diluição seriada e incubação em meio seletivo para a enumeração de micro-organismos cultiváveis; incubação em substrato seletivo e leitura em espectrofotômetro para as atividades enzimáticas; as características químico-físicas seguiram metodologias convencionais de análises de solo. Os resultados indicaram que as atividades microbiológicas são alteradas de acordo com o período de coleta, onde o primeiro ano apresentou os maiores resultados para as variáveis Respiração Basal (RB), Quociente metabólico (qMet), Bactérias Totais, Fungos Totais, Actinomicetos, Celulolíticos, $\beta$-glicosidase e Fosfatase Ácida. A correlação entre todas as variáveis, coletas e manejos, identificou que os fungos são responsáveis pela atividade da maioria das enzimas, além de sofrer influência das variáveis químicas: acidez potencial, matéria orgânica e capacidade de troca de cátions. A correlação dentro de cada ano de avaliação evidenciou a dinâmica das enzimas com relação ao atributo magnésio. Conclui-se que houve maior variação em relação ao período de coleta do que em relação ao manejo adotado, além disso, a condição química tem correlação direta com a presença de fungos totais e atividade das enzimas do solo.

Palavras-chave: atividade enzimática; microbiologia do solo; sistemas integrados.

\section{Soil attributes in differential soil use and management systems in Mato Grosso, MT, Brazil}

\begin{abstract}
Different land use systems have been proposed and implemented in the central-west region of Brazil. These new techniques guarantee the recovery of degraded areas and the potentialization use them, and for this reason they have become increasingly frequent, which requires technical knowledge to confirm their viability. The objective of this work was to evaluate the chemical and microbiological attributes an area on Red-Yellow Dystrophic Latosol with three crop-livestock-forest integration systems and to compare them with a pasture and native forest area, in two evaluation years. The collections were carried out at a technological reference unit of Embrapa Agrossilvipastoril, in the north of Mato Grosso state. Soil microbiological analyzes were carried out with fumigation-incubation method for microbial biomass carbon determination and its derivatives; serial dilution and incubation in a selective medium for microorganisms cultivable enumeration; incubation in selective substrate and spectrophotometer reading for enzymatic activities; the chemical-physical characteristics followed conventional methodologies of soil analysis. The results indicate that microbiological activities are altered according to the collection period, where the first
\end{abstract}


year shows the highest results for the variables Soil Respiration (RB), Metabolic Quotient (qMet), Total Bacteria, Total Fungi, Actinomycetes, Cellulolytics, $\beta$-glycosidase and Acid Phosphatase. The correlation between all variables, collections and management, identified that the total fungi are responsible for the activity of most enzymes, in addition to being influenced by chemical variables: potential acidity, organic matter and cation exchange capacity. The correlation within each year of evaluation showed the enzymes dynamics with respect to the magnesium attribute. It is concluded that there was a greater variation in relation to the harvesting period than in relation to the management adopted. In addition, the chemical condition has a direct correlation with the presence of total fungi and soil enzyme activity.

Keywords: enzymatic activity; soil microbiology; integrated systems.

\section{Introdução}

As atividades agrícolas realizadas após a revolução verde geraram grandes mudanças no cenário agrícola nacional e mundial. Diante do emprego de práticas exploratórias durante décadas, os objetivos de produtividade foram alcançados com resultados jamais vistos, porém, diversas áreas apresentaram sinais de degradação, com baixa produtividade e comprometimento dos atributos do solo, o que gerou a necessidade do emprego de outras práticas agrícolas, que visassem recuperar as áreas degradadas e minimizar a abertura de novas áreas (ALVARENGA et al., 2012).

Entre as novas tecnologias de uso e manejo do solo, destaca-se os sistemas sustentáveis de produção, como por exemplo, o plantio direto na palha, que é o precursor do emprego de revolvimento mínimo do solo, e os sistemas integrados de produção agropecuária. Esses sistemas integrados vêm ganhando espaço nas propriedades rurais do Brasil. Os sistemas que integram diferentes espécies vegetais são apontados como uma estratégia de produção sustentável, pois pode integrar atividades agropecuárias e florestais numa mesma área, e buscar efeitos sinérgicos entre os componentes do agroecossistema (BALBINO et al., 2011).

O sistema que desenvolve atividades agrossilvipastoris na mesma área é denominado de integração lavoura-pecuária-floresta (ILPF). Neste sistema, os componentes são usados em manejo consorciado, rotacionado ou sucessão, visando melhorias na qualidade econômica, bem estar social e preservação do meio ambiente (ALVARENGA et al., 2012).

Entretanto, toda e qualquer conversão de florestas em áreas cultiváveis leva à mundanças adversas nas propriedades do solo, principalmente na microbiota, que é de fundamental importância para o solo, uma vez que é responsável pelo seu equilíbrio, pois regula os processos e transformações estruturais do ambiente (STAVI et al., 2012). A biomassa microbiana e sua atividade têm sido apontadas como as características mais sensíveis às alterações na qualidade do solo, causadas por mudanças de uso e práticas de manejo (NEVES et al., 2009).

Desta forma, para que os sistemas integrados sejam adotados como opções sustentáveis de manejo em áreas comerciais, é necessária a realização de pesquisas nas áreas já instaladas e a demonstração dos resultados provenientes das esferas físicas, químicas e microbiológicas do solo. $\mathrm{O}$ objetivo deste trabalho foi avaliar a influência de três diferentes conformações de integração lavoura-pecuáriafloresta de uma área sobre Latossolo VermelhoAmarelo Distrófico, textura argilosa, nas características químicas e microbiológicas do solo.

\section{Material e Métodos}

O experimento de campo foi instalado na Fazenda Gamada, localizada a 103'29" O e 5557'11" S. O solo é classificado como Latossolo Vermelho-Amarelo Distrófico (LVAd) com textura argilosa (SEPLAN-MT, 2014). O clima da região é classificado segundo Köppen como Aw, clima tropical com chuvas excessivas no verão e inverno seco (ROLIM et al., 2007). A região apresenta temperatura média anual de $26 \stackrel{\circ}{\circ} \mathrm{e}$ precipitação média anual de $2.500 \mathrm{~mm}$.

Para a implantação do experimento de integração, o pasto presente na área foi dessecado com glifosato (Roundup ${ }^{\circledR}$ ) e a cultura do arroz implantada no sistema de semeadura direta, dezembro de 2008. O plantio das árvores de eucalipto (Eucalyptus urograndis) ocorreu em janeiro de 2009, em três configurações: a) linha simples com 2 m de distância entre plantas e 20 
$m$ entre linhas; b) linhas duplas espaçadas de 3 $\mathrm{m}$, com $2 \mathrm{~m}$ entre plantas e $20 \mathrm{~m}$ entre conjuntos de filas duplas, e c) linhas triplas espaçadas de 3 $\mathrm{m}$, com $2 \mathrm{~m}$ entre plantas e $20 \mathrm{~m}$ entre conjuntos de filas triplas. Cada configuração ocupou uma área de 5 ha, totalizando 15 ha sob integração com eucalipto. A faixa de 20 metros foi ocupada por lavoura de soja (Glycine max) nas safras 2009/10 e 2010/11, seguido de milho (Zea mays) na safrinha e pasto (Urochloa ruziziensis) na entressafra. O pasto implantado em 2011 permaneceu na área até 2014 , compreendendo a todo o período de amostragem.

As amostras de solo foram coletadas em abril dos anos de 2012 e 2013, na profundidade de $0-20 \mathrm{~cm}$, no sentindo transversal às linhas de plantio de eucalipto, a 0, 3, 6 e $10 \mathrm{~m}$ à esquerda e à direita. Cada amostra foi composta por três subamostras de pontos próximos. Em cada unidade experimental foram retiradas quatro repetições de cada ponto amostral, ou seja, no total da integração lavoura-pecuária-floresta linha simples de eucalipto, foram retiradas 28 amostras, e o mesmo foi repetido nas configurações linhas duplas e triplas de eucalipto.

Amostras de solo foram também coletadas em área de pasto com o mesmo histórico da área da integração, porém mantida apenas com o capim desde 2008, e em área de floresta nativa. Nestes locais, foram obtidas quatro amostras compostas de três subamostras. Os locais de coleta foram tomados aleatoriamente dentro de uma área de 5 ha, na mesma profundidade.

As amostras foram acondicionadas em sacos de plástico identificados previamente e mantidas sob temperatura de $\pm 7{ }^{\circ} \mathrm{C}$ para $\mathrm{O}$ transporte. No laboratório as mesmas foram passadas em peneiradas de $2 \mathrm{~mm}$ de abertura de malha e armazenadas sob refrigeração a $\pm 7{ }^{\circ} \mathrm{C}$ até seu processamento.

O solo foi caracterizado quimicamente de acordo com Embrapa (1999).

Os atributos microbiológicos avaliados foram respiração basal (RB), carbono da biomassa microbiana (CBM) e quociente metabólico (qMet), e empregou-se a metodologia de Jenkinson e Powlson (1976), os cálculos foram efetuados segundo Alef e Nannipieri (1995); enumeração de bactérias cultiváveis, actinomicetos e fungos cultiváveis realizados por diluição seriada e plaqueamento spread plate em meio seletivo (WOLLUM, 1982); e atividade das enzimas $\beta$-glicosidase, fosfatase alcalina, fosfatase ácida, realizados pelo método de Tabatabai e Bremner (1969), e para a urease do solo utilizou-se a metodologia de Kandeler e Gerber (1988), as determinação das atividades enzimáticas foram realizadas por Tabatabai e Bremner (1969) para a $\beta$-glicosidase, Eivazi e Tabatabai (1977) para as fosfatase, e Kandeler e Gerber (1988) para urease.

Os resultados foram submetidos a teste não paramétrico de comparações múltiplas, teste de correlação e regressão de variáveis, com auxílio do pacote estatístico SPSS 19 (SPSS, 2010).

Aplicou o teste de Kruskal-Wallis para as comparações múltiplas entre os manejos avaliados, uma vez que não houve normalidade dos dados e o desenho experimental não obedeceram às premissas da estatística paramétrica (repetição, casualização e normalidade dos dados). Para a comparação dos anos avaliados (2012-2013) efetuou-se o teste T.

A correlação de Pearson foi empregada para três cenários, sendo eles: toda a variável independente do ano, e dentro de cada ano de avaliação. As variáveis com correlação significativa dentro de cada ano foram plotadas em teste de regressão e expressas em gráficos.

\section{Resultados e Discussão}

Inicialmente os dados resultantes das análises das distâncias dentro dos sistemas de integração lavoura-pecuária-floresta (ILPF) foram tratados de acordo com as coletas efetuadas, variáveis microbiológicas e químicas, porém não foram encontradas diferenças estatísticas significativas. Assim, optou-se por utilizar os resultados provenientes das distâncias 0 e $10 \mathrm{~m}$ para caracterizar os sistemas, e usa-los como repetições nos testes estatísticos realizados para comparar os sistemas.

Os atributos microbiológicos e químicos avaliados comportaram-se de forma diferenciada nos manejos adotados e nos anos avaliados. As variáveis relacionadas ao carbono da biomassa (carbono da biomassa microbiana - CBM, respiração basal - RB e quociente metabólico qMet) não apresentaram diferenças entre os manejos avaliados e coletas realizadas. Entretanto, foi possível observar que as médias do primeiro ano foram, na maioria dos casos, mais elevadas do que no segundo ano (Tabela 1 ).

Alguns autores relatam que a microbiota tende a se equilibrar em função do tempo de adoção de sistemas sustentáveis onde mantém, e eleva os valores de CBM e reduz os valores de RB 
(BALDINO et al., 2011), situação essa que foi observada no presente trabalho.

Por outro lado, a enumeração de bactérias e fungos cultiváveis, actinomicetos e celulolíticos, apresentaram diferenças estatísticas significativas entre os manejos e coletas avaliadas.

Os valores médios da enumeração de bactérias foram mais elevados no ano de 2012 do que em 2013 para a integração lavoura-pecuáriafloresta linha simples de eucalipto (ILPF1) e para a floresta. Vale ressaltar que para a ILPF1, o valor diminuiu praticamente a metade, e no caso da floresta, a diminuição foi muito mais drástica, cerca de 10 vezes.

Quando comparadas áreas nativas e demais uso do solo é comum encontrar uma população mais diversificada em solo sob ambientes não manejados, como florestas, entretanto estas se apresentam mais sensíveis a qualquer alteração (PREVIATI et al., 2012). Esta afirmação pode justificar a diminuição drástica do número de bactéria em área de floresta comparada a ILPF1.

Tabela 1. Caracterização microbiológica de um Latossolo Vermelho-Amarelo Distrófico (LVAd), submetidos a cinco manejos, três diferentes conformações de integração lavoura-pecuária-floresta (ILPF), sendo elas linhas simples de eucalipto (ILPF1), linha dupla de eucalipto (ILPF2) e linha tripla de eucalipto (ILPF3), pasto e floresta nativa, na profundidade de 0,0-0,20 cm, com dois anos de avaliação, coletas 2012 e 2013.

\begin{tabular}{|c|c|c|c|c|c|c|c|c|}
\hline \multirow{3}{*}{$\begin{array}{c}\text { Variável } \\
\text { CBM }\end{array}$} & \multirow{3}{*}{$\begin{array}{c}\text { Coleta } \\
2012\end{array}$} & \multicolumn{7}{|c|}{ Manejos } \\
\hline & & \multicolumn{2}{|c|}{ ILPF 1} & ILPF 2 & ILPF 3 & Pasto & \multicolumn{2}{|c|}{ Floresta } \\
\hline & & 699,56 & $\mathrm{aA}$ & 309,33 aA & 624,00 aA & 140,00 aA & 2600,00 & $\mathrm{aA}$ \\
\hline$\mu \mathrm{g}$ C g solo ${ }^{-1}$ & 2013 & 700,43 & $\mathrm{aA}$ & 508,84 aA & 565,75 aA & 171,51 aA & 547,55 & $\mathrm{aA}$ \\
\hline RB & 2012 & 619,60 & $\mathrm{aA}$ & 459,60 aA & 661,20 aA & 480,00 aA & 573,00 & aA \\
\hline$\mu \mathrm{g} \mathrm{CO}_{2} \mathrm{~g} \mathrm{solo}^{-1}$ & 2013 & 311,40 & $\mathrm{aA}$ & 266,52 aA & 409,65 aA & 383,82 aA & 350,74 & $\mathrm{aA}$ \\
\hline qMet & 2012 & 1,70 & $\mathrm{aA}$ & 2,34 aA & 1,73 aA & 7,49 aA & 1,19 & aA \\
\hline$\%$ & 2013 & 1,21 & $\mathrm{aA}$ & $0,69 \quad a B$ & 0,99 aA & 3,13 aA & 1,41 & $\mathrm{aA}$ \\
\hline Bactérias Totais & 2012 & $4,24 \mathrm{E}+05$ & $\mathrm{aA}$ & $3,50 E+05 \quad a b A$ & $3,71 E+05$ abA & $1,58 \mathrm{E}+05 \quad b A$ & $2,28 \mathrm{E}+05$ & $a b A$ \\
\hline UFC g solo ${ }^{-1}$ & 2013 & $2,01 E+05$ & $\mathrm{aB}$ & $3,19 E+05$ aA & $1,96 \mathrm{E}+05$ aA & $1,10 \mathrm{E}+05$ aA & $3,13 \mathrm{E}+04$ & $a B$ \\
\hline Fungos Totais & 2012 & $8,75 E+04$ & $\mathrm{aA}$ & $6,98 \mathrm{E}+04 \quad a b A$ & $5,14 E+04 \quad a b A$ & $2,25 E+04 \quad b A$ & $6,85 \mathrm{E}+04$ & $a b A$ \\
\hline UFC g solo ${ }^{-1}$ & 2013 & $3,33 \mathrm{E}+03$ & $\mathrm{aB}$ & $4,00 E+03 \quad a B$ & $8,67 \mathrm{E}+03 \quad \mathrm{aB}$ & $1,13 \mathrm{E}+04$ aA & $1,25 \mathrm{E}+04$ & $a B$ \\
\hline Actinomicetos & 2012 & $5,05 E+05$ & $a b A$ & $6,67 E+05$ aA & $5,18 \mathrm{E}+05 \mathrm{abA}$ & $2,35 E+05$ bA & $3,17 \mathrm{E}+05$ & $a b A$ \\
\hline UFC g solo ${ }^{-1}$ & 2013 & $3,37 E+05$ & $a b A$ & $3,83 \mathrm{E}+05 \quad \mathrm{aB}$ & $6,41 E+04 \quad a b B$ & $7,38 \mathrm{E}+04 \quad \mathrm{abA}$ & $1,79 \mathrm{E}+04$ & $b B$ \\
\hline Celulolíticos & 2012 & $5,45 \mathrm{E}+05$ & $a b A$ & $8,17 E+05$ aA & $6,43 E+05 a b A$ & $1,78 \mathrm{E}+05$ abA & $1,62 E+05$ & $\mathrm{bA}$ \\
\hline UFC g solo ${ }^{-1}$ & 2013 & $3,95 \mathrm{E}+05$ & $\mathrm{aA}$ & $3,05 E+05 \quad a b A$ & $1,17 E+05 \quad b B$ & $4,21 E+04 \quad a b B$ & $2,67 \mathrm{E}+04$ & $a b B$ \\
\hline$\beta$-glicosidase & 2012 & 408,68 & $\mathrm{aA}$ & 456,76 aA & 348,34 aA & 337,34 aA & 342,60 & $\mathrm{aA}$ \\
\hline $\begin{array}{l}\mu \mathrm{g} p \text {-nitrofenol } \mathrm{h}^{-1} \mathrm{~g} \\
\text { solo }\end{array}$ & 2013 & 46,89 & $a b B$ & 37,45 bB & 42,89 abB & 60,46 aB & 36,72 & $a b B$ \\
\hline Fosfatase alcalina & 2012 & 39,36 & bA & 55,89 abA & 66,80 aA & 56,93 abA & 43,69 & $a b A$ \\
\hline $\begin{array}{c}\mu \mathrm{g} p \text {-nitrofenol } \mathrm{h}^{-1} \mathrm{~g} \\
\text { solo }\end{array}$ & 2013 & 31,95 & $\mathrm{aA}$ & 60,19 aA & $33,37 \quad a B$ & 25,72 aB & 27,21 & $\mathrm{aA}$ \\
\hline Fosfatase ácida & 2012 & 65,68 & $a b A$ & 62,45 abA & 50,71 abA & 41,09 bA & 72,66 & aA \\
\hline $\begin{array}{l}\mu \mathrm{g} \mathrm{p} \text {-nitrofenol } \mathrm{h}^{-1} \mathrm{~g} \\
\text { solo }\end{array}$ & 2013 & 48,44 & $a B$ & $40,83 \quad a B$ & 45,05 aA & 36,17 aA & 40,05 & $a B$ \\
\hline Urease & 2012 & 64,87 & $a b B$ & $62,35 a b B$ & 82,99 aB & 53,31 abB & 29,21 & $b B$ \\
\hline 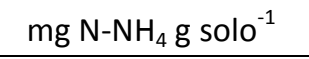 & 2013 & 7146,07 & $\mathrm{bA}$ & $7692,95 \mathrm{abA}$ & 13297,94 aA & 13133,17 abA & 9871,31 & $a b A$ \\
\hline
\end{tabular}


Seguindo a mesma tendência, os valores médios de enumeração de fungos foram mais elevados no ano de 2012 do que em 2013, com diminuição de mais de 10 vezes para todos os manejos, exceção para pasto que diminuiu a metade do valor.

A maior enumeração de bactérias e fungos em áreas sob ILPF, no primeiro ano de avaliação, em comparação, especialmente, com área de pasto, pode ser justificada pela presença de diferentes espécies vegetais que foram cultivadas em rotação ou sucessão nos anos anteriores a data de coleta, ou seja, ao histórico da área, pois o acúmulo de matéria orgânica diferenciada favoreceu o crescimento e atividade microbiana na camada superficial do solo (BLAGODATSKAYA; KUZYAKOV, 2013).

Os valores médios da enumeração de actinomicetos apresentaram diferenças de acordo com o manejo adotado. No sistema de integração lavoura-pecuária-floresta linha dupla de eucalipto (ILPF2) a diminuição média, do ano de 2012 para 2013, foi de metade do seu valor, enquanto que, para integração lavoura-pecuáriafloresta linha tripla de eucalipto (ILPF3) e floresta a diminuição, para o mesmo período, foi de até 10 vezes. Além disso, observou-se que, em todos os manejos, houve redução do número de actinomicetos ao longo do tempo de avaliação, e os sistemas de ILPF apresentou as maiores médias em comparação ao pasto e floresta nativa.

Para os valores médios da enumeração de celulolíticos, a enumeração seguiu a mesma tendência observada para os actinomicetos, entretanto para a ILPF3 a diminuição foi de 6 vezes o valor do primeiro ano, e para pasto $e$ floresta a diminuição foi ainda mais drástica, cerca de 10 vezes.

A diferença de habitats pode justificar a presença de um maior número de unidades formadoras de colônias (UFC) de actinomicetos e celulolíticos nos sistemas de ILPF, pois os habitats apresentam grandes diferenças em suas características, onde as integrações possuem matéria orgânica diferenciada e exploração rizosférica em diferentes profundidades, de maneira que um habitat favorável ao crescimento de uma população de organismos pode ser extremamente nocivo a outro (PREVIATI et al., 2012).

Além disso, alguns trabalhos relatam que a serapilheira de áreas com plantio de eucalipto apresenta substâncias com atividade antimicrobiana, que, ao passar do tempo de adoção do sistema, pode dificultar a sobrevivência e o crescimento de diferentes grupos de micro-organismos do solo, especialmente os mais sensíveis como os actinomicetos (ALVARENGA et al., 2012).

A atividade dos micro-organismos está associada diretamente com a produção de enzimas. Desta forma, observa-se que a atividade das enzimas $\beta$-glicosidase, fosfatase alcalina e fosfatase ácida foram superiores no primeiro ano de avaliação em comparação ao segundo.

A atividade da $\beta$-glicosidase variou mais de 10 vezes nos sistemas ILPF2 e floresta, do ano de 2012 para 2013. Observa que a atividade desta enzima manteve na casa centesimal no primeiro ano, enquanto no segundo ano todos os manejos apresentam quedas de atividade para a casa decimal.

A $\beta$-glicosidase é uma das enzimas mais comuns encontradas no solo, e atua na etapa final do processo de decomposição da celulose. Essa enzima é responsável pela hidrólise dos resíduos de celobiose, formando o açúcar simples $\beta$-D-glicose, ou seja, libera glicose como fonte de energia para os micro-organismos (TABATABAI, 1994; MAKOI; NDAKIDEMI, 2008). A partir dessa afirmação, pode-se inferir que o processo de degradação da matéria orgânica, rica em carbono, proveniente dos resíduos vegetais diversos, teve acentuada atividade da enzima $\beta$ glicosidase no primeiro ano, e então, com a redução da disponibilidade de matéria orgânica no segundo ano a atividade desta enzima foi reduzida.

Observa-se que a atividade, das fosfatases também sofreram redução ao longo do tempo, entretanto essa redução foi menos expressiva se comparada a $\beta$-glicosidase. Carneiro e colaboradores (2008) sugerem que a $\beta$-glicosidase é responsável pela produção de uma fonte importante de energia para os microorganismos do solo, e alterações no solo resultam em redução acentuada da atividade desta enzima devido a sua fragilidade, por outro a fosfatase apresenta reabilitação rápida da atividade, não sendo tão influenciada por alterações no solo.

A área ILPF3 apresentou a maior média de atividade de fosfatase alcalina no ano de 2012 e reduziu à metade no ano de 2013. O mesmo resultado foi observado para a área de pasto, 
sendo que o resultado de 2013, neste sistema, foi o menor valor encontrado para esta atividade.

$\mathrm{Na}$ avaliação da fosfatase ácida, os manejos que apresentaram diferenças estatísticas entre as coletas foram ILPF1, ILPF2 e floresta. A floresta apresentou a maior atividade encontrada, com a média para o ano de 2012 de $72,66 \mu \mathrm{g}$ p-nitrofenol $\mathrm{h}^{-1} \mathrm{~g}$ solo, enquanto no segundo apresentou a menor média desta enzima, com 40,05 $\mu \mathrm{g}$ p-nitrofenol $\mathrm{h}^{-1} \mathrm{~g}$ solo.

A atividade das fosfatases, sejam elas alcalina ou ácida, está diretamente relacionada aos teores de fósforo no solo, dessa forma a deficiência deste nutriente irá interferir no desemprenho desta atividade enzimática (GOMIDE et al., 2011). Além disso, as fosfatases são dependentes das condições de $\mathrm{pH}$ que o solo apresenta. Neste estudo foram encontrados resultados similares para ambas às enzimas em todos os sistemas avaliados.

A produção de enzimas pelos microorganismos, ou seja, a atividade microbiana está condicionada a inúmeros fatores, especialmente aqueles que favorecem a vida microbiana. Além disso, é importante ressaltar que apenas a presença de matéria orgânica não é suficiente para que se inicie sua degradação. As condições locais de água e temperatura, bem como, a disponibilidade de outros nutrientes para os micro-organismos são fatores extremamente relevantes para seus processos bioquímicos (REIS JUNIOR; MENDES, 2009; GOMIDE et al., 2011).

Oposto ao observado para as enzimas $\beta$ glicosidase e fosfatases, os valores de urease foram maiores no ano de 2013 e foi diferente estatisticamente do ano de 2012, para todos os manejos avaliados. A atividade desta enzima variou de 29,21 a $13297,94 \mathrm{mg} \mathrm{N}-\mathrm{NH}_{4}$ g solo $^{-1}$ do ano de 2012 para 2013, em solo sob floresta e ILPF3, respectivamente.

A variação da urease pode estar associada ao incremento de matéria orgânica nitrogenada aos sistemas. Observando o histórico da área, remete ao segundo ano um maior período de pastejo e, consequentemente, incremento de resíduo bovino, rico em ureia. A qualidade dos resíduos depositados, bem como, as condições locais de $\mathrm{pH}$, temperatura e umidade são os principais fatores que afetam as atividades enzimáticas do solo (EKENLER; TABATABAl, 2003; MENDES et al., 2009).

A floresta pode ter sido influenciada pelo mesmo fato, uma vez que, a coleta se deu após o período de chuvas da região, e a pluviosidade pode ter levado essa matéria orgânica das áreas sob pastejo para a floresta.

A urease é uma enzima produzida, quase que exclusivamente, por micro-organismos do solo, sejam eles bactérias, fungos ou archeas, que facilitam a hidrólise da molécula de ureia em amônia, com liberação de $\mathrm{CO}_{2}$ e $\mathrm{H}_{2} \mathrm{O}$, sendo verificado que a atividade da urease está associada ao tamanho da população, à época de avaliação e principalmente à presença de matéria orgânica nitrogenada (LISBOA et al., 2014).

As enzimas apresentam grande importância para os solos, pois grande parte das transformações bioquímicas que ocorrem neste ambiente é dependente ou relacionada à presença e atividade de enzimas. A avaliação da atividade enzimática pode ser útil para indicar se um solo está desempenhando adequadamente os processos que estão intimamente ligados a sua qualidade, como a fertilidade (REIS JUNIOR; MENDES, 2009).

A avaliação dos atributos químicos mostrou variação entre os manejos no primeiro ano, para a maioria das variáveis, enquanto o segundo ano de avaliação apresentou diferenças estatísticas apenas para o fósforo $(P)$. Em relação ao período de coleta, apenas as variáveis magnésio $(\mathrm{Mg})$, acidez potencial $(\mathrm{H}+\mathrm{Al})$, matéria orgânica (M.O) e capacidade de troca de cátion (CTC) apresentaram variação, sendo maiores no primeiro ano comparado ao segundo (Tabela 2).

Os valores médios de $P$ apresentaram-se de forma semelhante em ambos os anos. Vale ressaltar que a ILPF1 apresentou maior média, com 6,63 e $4,40 \mathrm{mg} \mathrm{dm}^{3}$, e pasto a menor, com 1,63 e $1,11 \mathrm{mg} \mathrm{dm}^{3}$, para o ano de 2012 e 2013, respectivamente, e não foram evidenciadas diferenças significativas entre os anos. 
Tabela 2. Caracterização físico-química de um Latossolo Vermelho-Amarelo Distrófico (LVAd), submetidos a cinco manejos, três diferentes conformações de integração lavoura-pecuária-floresta (ILPF), sendo elas linhas simples de eucalipto (ILPF1), linha dupla de eucalipto (ILPF2) e linha tripla de eucalipto (ILPF3), pasto e floresta nativa, na profundidade de 0,0-0,20 cm, com dois anos de avaliação, coleta 2012 e 2013.

\begin{tabular}{|c|c|c|c|c|c|c|c|c|c|c|c|}
\hline \multirow{3}{*}{$\begin{array}{c}\text { Variável } \\
\text { pH }\end{array}$} & \multirow{3}{*}{$\begin{array}{c}\text { Coleta } \\
2012\end{array}$} & \multicolumn{10}{|c|}{ Manejos } \\
\hline & & \multicolumn{2}{|c|}{ ILPF 1} & \multicolumn{2}{|c|}{ ILPF 2} & \multicolumn{2}{|c|}{ ILPF 3} & \multicolumn{2}{|c|}{ Pasto } & \multicolumn{2}{|c|}{ Floresta } \\
\hline & & 5,51 & $\mathrm{aA}$ & 5,78 & $\mathrm{aA}$ & 5,60 & $\mathrm{aA}$ & 5,53 & $\mathrm{aA}$ & 5,09 & $\mathrm{aA}$ \\
\hline $\mathrm{H}_{2} \mathrm{O}$ & 2013 & 5,58 & $\mathrm{aA}$ & 5,53 & $\mathrm{aA}$ & 5,45 & $\mathrm{aA}$ & 5,87 & $\mathrm{aA}$ & 5,13 & $\mathrm{aA}$ \\
\hline $\mathbf{P}$ & 2012 & 6,63 & $a A$ & 4,32 & $a b A$ & 3,26 & $a b A$ & 1,63 & $\mathrm{bA}$ & 2,49 & $a b A$ \\
\hline $\mathrm{mg} \mathrm{dm}^{-3}$ & 2013 & 4,40 & $\mathrm{aA}$ & 2,66 & $a b A$ & 2,15 & $a b A$ & 1,11 & $\mathrm{bA}$ & 3,30 & $a b A$ \\
\hline $\mathbf{K}$ & 2012 & 75,92 & $a b A$ & 82,05 & $a b A$ & 112,64 & $\mathrm{aA}$ & 24,06 & $\mathrm{bA}$ & 57,28 & $a b A$ \\
\hline Ppm & 2013 & 55,40 & $\mathrm{aA}$ & 57,48 & $\mathrm{aA}$ & 69,31 & $\mathrm{aA}$ & 33,51 & $\mathrm{aA}$ & 57,38 & $\mathrm{aA}$ \\
\hline $\mathrm{Ca}$ & 2012 & 1,29 & $\mathrm{aA}$ & 2,09 & $\mathrm{aA}$ & 1,62 & $\mathrm{aA}$ & 1,10 & $\mathrm{aA}$ & 1,00 & $\mathrm{aA}$ \\
\hline $\begin{array}{c}\mathrm{cmol}_{\mathrm{c}} \\
\mathrm{dm}^{-3}\end{array}$ & 2013 & 1,29 & $\mathrm{aA}$ & 1,37 & $\mathrm{aA}$ & 1,31 & $\mathrm{aA}$ & 1,27 & $\mathrm{aA}$ & 2,84 & $\mathrm{aA}$ \\
\hline $\mathrm{Mg}$ & 2012 & 0,90 & $\mathrm{aA}$ & 0,87 & $\mathrm{aA}$ & 1,27 & $\mathrm{aA}$ & 0,63 & $\mathrm{aA}$ & 0,73 & $\mathrm{aA}$ \\
\hline $\begin{array}{l}\mathrm{cmol}_{\mathrm{c}} \\
\mathrm{dm}^{-3}\end{array}$ & 2013 & 0,70 & $\mathrm{aA}$ & 0,76 & $\mathrm{aA}$ & 0,55 & $\mathrm{aB}$ & 0,34 & $\mathrm{aA}$ & 0,93 & $\mathrm{aA}$ \\
\hline Al & 2012 & 0,24 & $a b A$ & 0,17 & $\mathrm{aA}$ & 0,18 & $a b A$ & 0,14 & $\mathrm{bA}$ & 0,65 & $\mathrm{aA}$ \\
\hline $\begin{array}{c}\mathrm{cmol}_{\mathrm{c}} \\
\mathrm{dm}^{-3}\end{array}$ & 2013 & 0,27 & $\mathrm{aA}$ & 0,22 & $\mathrm{aA}$ & 0,23 & $\mathrm{aA}$ & 0,30 & $\mathrm{aA}$ & 0,37 & $\mathrm{aA}$ \\
\hline $\mathrm{H}+\mathrm{Al}$ & 2012 & 5,60 & $a b A$ & 5,81 & $a b A$ & 6,66 & $a b A$ & 4,20 & $\mathrm{bA}$ & 7,73 & $\mathrm{aA}$ \\
\hline $\begin{array}{c}\mathrm{cmol}_{\mathrm{c}} \\
\mathrm{dm}^{-3}\end{array}$ & 2013 & 3,51 & $\mathrm{aB}$ & 3,35 & $\mathrm{aB}$ & 3,93 & $\mathrm{aB}$ & 3,15 & $\mathrm{aB}$ & 3,38 & $\mathrm{aB}$ \\
\hline M.O & 2012 & 3,73 & $a A$ & 3,45 & $a b A$ & 3,54 & $a b A$ & 2,87 & $\mathrm{bA}$ & 3,78 & $a b A$ \\
\hline$\%$ & 2013 & 2,06 & $\mathrm{aB}$ & 2,09 & $\mathrm{aB}$ & 2,20 & $\mathrm{aB}$ & 1,91 & $\mathrm{aB}$ & 2,07 & $\mathrm{aA}$ \\
\hline $\mathbf{S}$ & 2012 & 2,38 & $\mathrm{aA}$ & 3,17 & $\mathrm{aA}$ & 3,18 & $\mathrm{aA}$ & 1,79 & $\mathrm{aA}$ & 1,88 & $\mathrm{aA}$ \\
\hline $\begin{array}{l}\mathrm{cmol}_{\mathrm{c}} \\
\mathrm{dm}^{-3}\end{array}$ & 2013 & 2,13 & $\mathrm{aA}$ & 2,26 & $\mathrm{aA}$ & 2,03 & $\mathrm{aA}$ & 1,70 & $\mathrm{aA}$ & 3,03 & $\mathrm{aA}$ \\
\hline СТС T & 2012 & 7,97 & $a b A$ & 8,98 & $a b A$ & 9,84 & $a A$ & 5,99 & $\mathrm{bA}$ & 9,61 & $a b A$ \\
\hline $\begin{array}{l}\mathrm{cmol}_{\mathrm{c}} \\
\mathrm{dm}^{-3}\end{array}$ & 2013 & 5,64 & $\mathrm{aB}$ & 5,60 & $\mathrm{aB}$ & 5,95 & $\mathrm{aB}$ & 4,85 & $\mathrm{aB}$ & 6,41 & $\mathrm{aA}$ \\
\hline CTC $t$ & 2012 & 2,62 & $a b A$ & 3,35 & $\mathrm{aA}$ & 3,37 & $a b A$ & 1,93 & $\mathrm{bA}$ & 2,53 & $a b A$ \\
\hline $\begin{array}{l}\mathrm{cmol}_{\mathrm{c}} \\
\mathrm{dm}^{-3}\end{array}$ & 2013 & 2,40 & $\mathrm{aA}$ & 2,47 & $\mathrm{aA}$ & 2,26 & $\mathrm{aA}$ & 2,00 & $\mathrm{aA}$ & 3,40 & $\mathrm{aA}$ \\
\hline V & 2012 & 29,12 & $a b A$ & 34,90 & $\mathrm{aA}$ & 31,46 & $a b A$ & 29,97 & $a b A$ & 19,55 & $\mathrm{bA}$ \\
\hline$\%$ & 2013 & 36,83 & $\mathrm{aA}$ & 38,90 & $\mathrm{aA}$ & 33,09 & $\mathrm{aA}$ & 35,01 & $\mathrm{aA}$ & 41,85 & $\mathrm{aA}$ \\
\hline $\mathrm{m}$ & 2012 & 11,07 & $a b A$ & 6,20 & $\mathrm{bA}$ & 6,68 & $a b A$ & 7,15 & $a b A$ & 27,94 & $\mathrm{aA}$ \\
\hline$\%$ & 2013 & 15,02 & $\mathrm{aA}$ & 12,69 & $\mathrm{aA}$ & 13,90 & $\mathrm{aA}$ & 15,53 & $\mathrm{aA}$ & 26,49 & $\mathrm{aA}$ \\
\hline Argila & 2012 & 456,00 & $\mathrm{aA}$ & 456,00 & $\mathrm{aA}$ & 456,00 & $\mathrm{aA}$ & 456,00 & $\mathrm{aA}$ & 456,00 & $\mathrm{aA}$ \\
\hline $\mathrm{g} \mathrm{Kg}^{-1}$ & 2013 & 456,00 & $\mathrm{aA}$ & 456,00 & $\mathrm{aA}$ & 456,00 & $\mathrm{aA}$ & 456,00 & $\mathrm{aA}$ & 456,00 & $\mathrm{aA}$ \\
\hline Silte & 2012 & 177,00 & $\mathrm{aA}$ & 177,00 & $\mathrm{aA}$ & 177,00 & $\mathrm{aA}$ & 177,00 & $\mathrm{aA}$ & 177,00 & $\mathrm{aA}$ \\
\hline $\mathrm{g} \mathrm{Kg}^{-1}$ & 2013 & 177,00 & $\mathrm{aA}$ & 177,00 & $\mathrm{aA}$ & 177,00 & $\mathrm{aA}$ & 177,00 & $\mathrm{aA}$ & 177,00 & $\mathrm{aA}$ \\
\hline Areia & 2012 & 376,00 & $\mathrm{aA}$ & 376,00 & $\mathrm{aA}$ & 376,00 & $\mathrm{aA}$ & 376,00 & $\mathrm{aA}$ & 376,00 & $\mathrm{aA}$ \\
\hline $\mathrm{g} \mathrm{Kg}^{-1}$ & 2013 & 376,00 & $\mathrm{aA}$ & 376,00 & $\mathrm{aA}$ & 376,00 & $\mathrm{aA}$ & 376,00 & $\mathrm{aA}$ & 376,00 & $\mathrm{aA}$ \\
\hline
\end{tabular}

* Médias seguidas de mesma letra, minúscula na linha e maiúscula na coluna, não diferem entre si pelo teste não paramétrico de comparações múltiplas de Kruskal-Wallis e teste T;

** ILPF1: integração lavoura-pecuária-floresta linha simples de eucalipto; ILPF2: linha dupla de eucalipto; ILPF3: linha tripla de eucalipto; $\mathbf{H + A l}$ : acidez potencial; $\mathbf{S}$ : soma de bases; CTC T: capacidade de troca de cátions em $\mathrm{pH}$ 7; CTC t: capacidade de troca de cátions efetiva; V: saturação por bases; m: saturação por Al 
Em função do teor médio de argila na área de estudo ter sido $456,0 \mathrm{~g} \mathrm{~kg}^{-1}$, os solos estudados apresentam teor baixo de P (MARTHA $J R$ et al., 2007), porém a presença de maiores médias de $\mathrm{P}$ nas áreas de ILPF sugere que a ciclagem desse elemento está ocorrendo com maior intensidade nessas áreas, em ambos os anos, comparado ao pasto. Este resultado possivelmente está relacionado com a disponibilização de $P$ pela atividade de degradação da matéria orgânica e morte dos micro-organismos (CARNEIRO et al., 2008).

$O P$ orgânico é uma fonte potencial de $P$ disponível às plantas, graças à ciclagem biológica, à síntese e exsudação de fosfatases, pelos microorganismos e raízes das plantas (ROSS et al., 1995). Em trabalho realizado com a finalidade de verificar a fertilidade do solo com manejo de sistema misto, também foi verificado acréscimos nos teores de P (SANTOS et al., 2012).

O potássio (K) apresentou diferenças significativas entre os manejos no primeiro ano, onde ILPF3 apresentou a maior média, 112,64 ppm, e pasto a menor, 33,51 ppm, verificadas para os dois anos. A classificação do $\mathrm{K}$ no solo, tomando os resultados de CTC T, apresenta teor baixo de K (MARTHA JR et al., 2007).

$O$ elemento $K$ não é parte integrante de compostos orgânicos, assim, não está localizado na parte estrutural dos seres vivos, porém ele atua na atividade hídrica das células, principalmente na atividade de abre-fecha dos estômatos (SILVEIRA; MALAVOLTA, 2000), o que o torna indispensável no desenvolvimento vegetal.

As variáveis, alumínio (Al) e $\mathrm{H}+\mathrm{Al}$ apresentaram de forma diferente entre os manejos, no ano de 2012. O Al apresentou maior na floresta, e menor em área de pasto, com 0,65 e $0,14{ }_{c} \mathrm{~mol} \mathrm{dm}^{3}$, respectivamente, os solos caracterizam-se por apresentar teor baixo de Al (TOMÉ JÚNIOR, 1997).

Os baixos teores de Al são desejáveis, pois as altas concentrações no solo são responsáveis pela inibição do crescimento das raízes e influenciam negativamente na absorção de água e $\mathrm{P}$, e a $\mathrm{H}+\mathrm{Al}$ dos solos tem relação direta com a matéria orgânica presente, o que sugere boas condições de aporte desta nos solos estudados (CRUZ et al., 2008).

Trabalhos realizados comparando diferentes espécies florestais adotadas nos sistemas de ILPF apontam que a adoção de eucalipto como espécie floresta na ILPF tende a favorecer um menor teor de Al no solo (AZEVEDO et al., 2010).

Os valores de M.O foram alterados de acordo com os manejos, no primeiro ano. $O$ maior teor foi encontrado na floresta e o menor em área de pasto, 3,78 e 2,87 \%, respectivamente. De acordo com Embrapa (1999), os solos são reconhecidos como valores médios de concentração de M.O. Estoques de M.O estão relacionados ao balanço da razão entre a formação/decomposição do carbono orgânico do solo (COS), baixos teores de M.O prejudicam a retenção de nutrientes, como $\mathrm{K}, \mathrm{Ca}$ e Mg (CHIODINI et al., 2013) e levam a necessidade de adição de fertilizantes com maior frequência.

A M.O diminuiu com o tempo de avaliação, no segundo ano apresentou menor teor para todos os tratamentos, com diferenças estatísticas significativas, exceto para floresta. Essa situação remete a sustentabilidade do sistema agrícola; sabe-se que para atingir a utilização sustentável do solo agrícola deve-se aumentar o estoque da M.O do solo para manter o nível próximo ao da área original (BAYER et al., 2006).

Desta maneria, há um grande interesse no desenvolvimento de práticas agrícolas que reduzam a degradação do solo e tenham potencial de aumentar a sustentabilidade agrícola e conservação do solo (RICHARDSON; SIMPSON, 2011), entretanto necessita-se de investigações em longo prazo de manejos diferenciados, a fim de comprovar tais potenciais.

$\mathrm{Em}$ respostas as condições supracitadas, as variáveis químicas CTC, $V$ e $m$ apresentaram as mesmas tendências dos elementos químicos.

Os baixos valores encontrados para CTC e $\checkmark$ caracterizam os solos estudados, como solos distróficos ou pobres, e está relacionado com a capacidade de reserva de nutrientes. Assim, potencializar a presença microbiana e, mais ainda, sua atividade, são medidas sustentáveis para o solo, uma vez que irá aumentar e permitir a ciclagem de nutrientes e a estabilidade do sistema.

Resultados da literatura sugerem que sistemas florestais apresentam a vantagem de retirar nutrientes dos horizontes mais profundos dos solos e promover a ciclagem de nutrientes para horizontes superficiais por meio da serapilheira depositada na superfície do solo, o que gera equilíbrio ecológico ao longo do tempo 
de adoção desses manejos (SCHUMACHER et al., 2008).

A correlação entre variáveis apresentou maior em número e em significância quando se analisou o conjunto de variáveis para os dois anos de coleta (Tabela 3).

Houve correlação positiva entre váriaveis microbiológicas e químicas do solo, onde observou relação positiva entre as atividades enzimática $\beta$-glicosidase e urease, enumeração dos micro-organismos, fungos totais $e$ celulolíticos, $\mathrm{H}+\mathrm{Al}, \mathrm{M} . \mathrm{O}$ e CTC T. Por outro lado, ocorreu correlação negativa para a urease em relação a todas as demais variáveis.
A interação entre todas as variáveis sugere que, os fungos são os promotores da atividade da $\beta$-glicosidase e fosfatase ácida, bem como, há relação direta com a atividade celulolítica no solo. Além disso, houve correlação forte com a M.O, o que era esperado, uma vez que as atividades correlatas a essa comunidade microbiológica necessitam de substrato para sua funcionalidade e, condições químicas que favoreçam suas atividades (TABATABAl; BREMNER, 1969; GOMIDE et al., 2011), o que pode ser visualizado com correlação moderada entre $\mathrm{H}+\mathrm{Al}$ e CTC T.

Tabela 3. Correlações significativas entre as variáveis de solo para três cenários: a) todas as variáveis e tratamentos nos dois anos de avaliação, coletas 2012 e 2013; b) todas as variáveis e tratamentos apenas no primeiro ano de avaliação, coleta 2012; c) todas as variáveis e tratamentos apenas no segundo ano de avaliação, coleta 2013.

\begin{tabular}{|c|c|c|c|c|c|c|c|c|}
\hline & & & & & & & & a) \\
\hline & B-glicosidase & Fungos totais & Celulolíticos & Urease & Fosf. Ácida & $\mathrm{H}+\mathrm{Al}$ & M.O & CTC T \\
\hline B-glicosidase & 1 & & & & & & & \\
\hline Fungos totais & 0,83 & 1 & & & & & & \\
\hline Celulolíticos & 0,55 & 0,46 & 1 & & & & & \\
\hline Urease & $-0,72$ & $-0,66$ & $-0,51$ & 1 & & & & \\
\hline Fosf. Ácida & 0,59 & 0,65 & ns & $-0,49$ & 1 & & & \\
\hline $\mathrm{H}+\mathrm{Al}$ & 0,66 & 0,69 & 0,32 & $-0,60$ & 0,55 & 1 & & \\
\hline M.O & 0,74 & 0,74 & 0,31 & $-0,64$ & 0,56 & 0,75 & 1 & \\
\hline CTC T & 0,64 & 0,64 & 0,41 & $-0,63$ & 0,45 & 0,84 & 0,67 & 1 \\
\hline
\end{tabular}

\begin{tabular}{ccc}
\hline & & b) \\
\hline & Actinomicetos & $\mathbf{M g}$ \\
\hline Celulolítico & 0,84 & \\
\hline Fosf. Alcalina & $\mathrm{ns}$ & 0,47 \\
\hline Urease & $\mathrm{ns}$ & 0,43 \\
\hline & & $\mathbf{c})$ \\
\hline & Actinomicetos & $\mathbf{M g}$ \\
\hline Celulolítico & 0,86 & \\
\hline Fosf. Alcalina & $\mathrm{ns}$ & 0,53 \\
\hline Urease & $\mathrm{ns}$ & $-0,44$ \\
\hline
\end{tabular}

Por outro lado, a urease apresentou correlação moderada e negativa com as variáveis $\beta$-glicosidase, fungos totais e celulolíticos. Assumindo, que os fungos são responsáveis pela atividade dessas variáveis, uma vez obtido correlação negativa a ele, também ocorrerá com as demais. Uma possível explicação para a inversão na correlação, é que a atividade da urease promove a formação de carbonatos e, consequentemente, aumenta a alcalinidade do meio (BREMNER; KROGMEIER, 1989; SONDI; SALOPEK-SONDI, 2005).

Como discutido anteriormente, a atividade microbiológica é condicionada a presença de substrato e características ambientais (EKENLER; TABATABAI, 2003; MENDES et al., 2009; GOMIDE et al., 2011) e o teste de correlação entre todas as variáveis confirma e reforça esta afirmação. 
As correlações dentro do primeiro ano de avaliação (2012) apresentaram correlação significativa e forte entre celulolíticos e actinomicetos, e fraca para fosfatase alcalina e magnésio $(\mathrm{Mg})$, e urease e $\mathrm{Mg}$. No segundo ano de avaliação, 2013, a mesma dinâmica de correlações foi visualizada, porém houve correlação negativa entre a variável urease e $\mathrm{Mg}$ (Tabela 3.b-c).

As regressões entre as variáveis com correlação moderada a forte, nos dois anos de avaliação, estão apresentadas nas figuras 1, 2 e 3 .

Figura 1. Comparação entre as regressões das variáveis enumeração de celulolíticos em função da enumeração de actinomicetos nos dois anos de avaliação, 2012 e 2013.

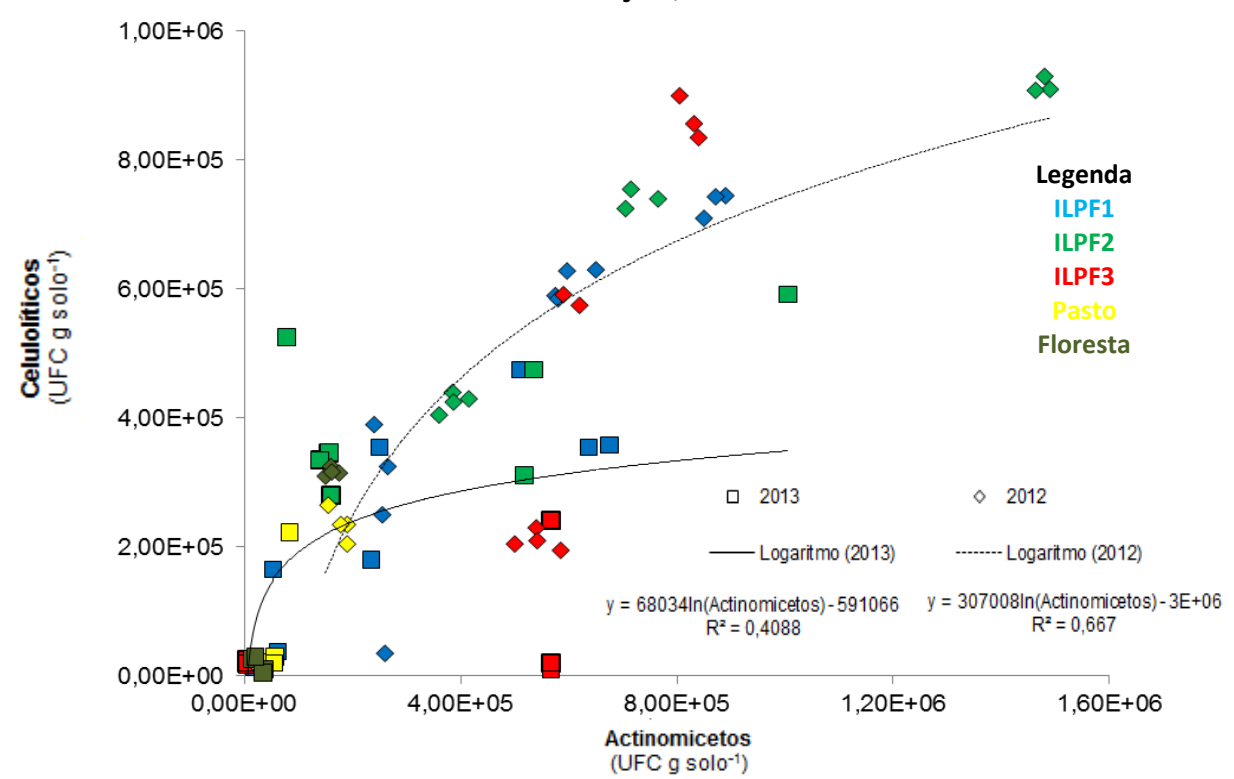

Entre outros grupos de micro-organismos do solo, os actinomicetos são, em especial, com potencial capacidade celulolítica de converter a biomolécula celulose em formas de açúcar assimiláveis que, muitas vezes, são utilizadas como fonte de energia pela própria comunidade microbiana do solo (NURKANTO, 2009), e há tendência em aumentar a degradação com o aumento do número de actinomicetos presentes no ambiente, o que foi observado neste trabalho.

Os actinomicetos são grupos de bactérias de importância ecológica pela sua capacidade em produção de enzimas e degradação de composto de difícil degradação, onde, por exemplo, os fungos não conseguem atuar com eficácia (RAMESH; MATHIVANAN, 2009).

Por outro lado, a ação das enzimas é mediada por compostos químicos, e essa afirmação pode ser evidenciada pela relação entre as enzimas fosfatase alcalina e urease com
O modelo logarítmico foi o que melhor ajustou para as variáveis, enumeração de celulolíticos e enumeração de actinomicetos em ambos os anos de avaliação, entretanto, o coeficiente de correlação foi menor no primeiro ano em relação ao segundo. Assim, no primeiro ano, 2012, 40,8 \% da enumeração de celulolíticos pode ser explicada pela enumeração de actinomicetos, enquanto que no segundo ano, 2013 , essa percentagem foi de $66,7 \%$ (Figura 1 ). (UFC g solo-1)

o $\mathrm{Mg}$, o único nutriente que se correlacionou significativamente com essas enzimas (Figuras $2 \mathrm{e}$ 3).

O modelo exponencial foi o que melhor se ajustou para a regressão entre fosfatase alcalina e Mg. Entretanto, o coeficiente de determinação foi baixo para ambos os anos. No primeiro ano (2012), apenas $10,8 \%$ da fosfatase alcalina pode ser explicada pelo $\mathrm{Mg}$, e no segundo ano (2013) essa percentagem foi de 18,4 $\%$ (Figura 2). 
Figura 2. Comparação entre as regressões das variáveis fosfatase alcalina em função do magnésio (Mg) nos dois anos de avaliação, 2012 e 2013.

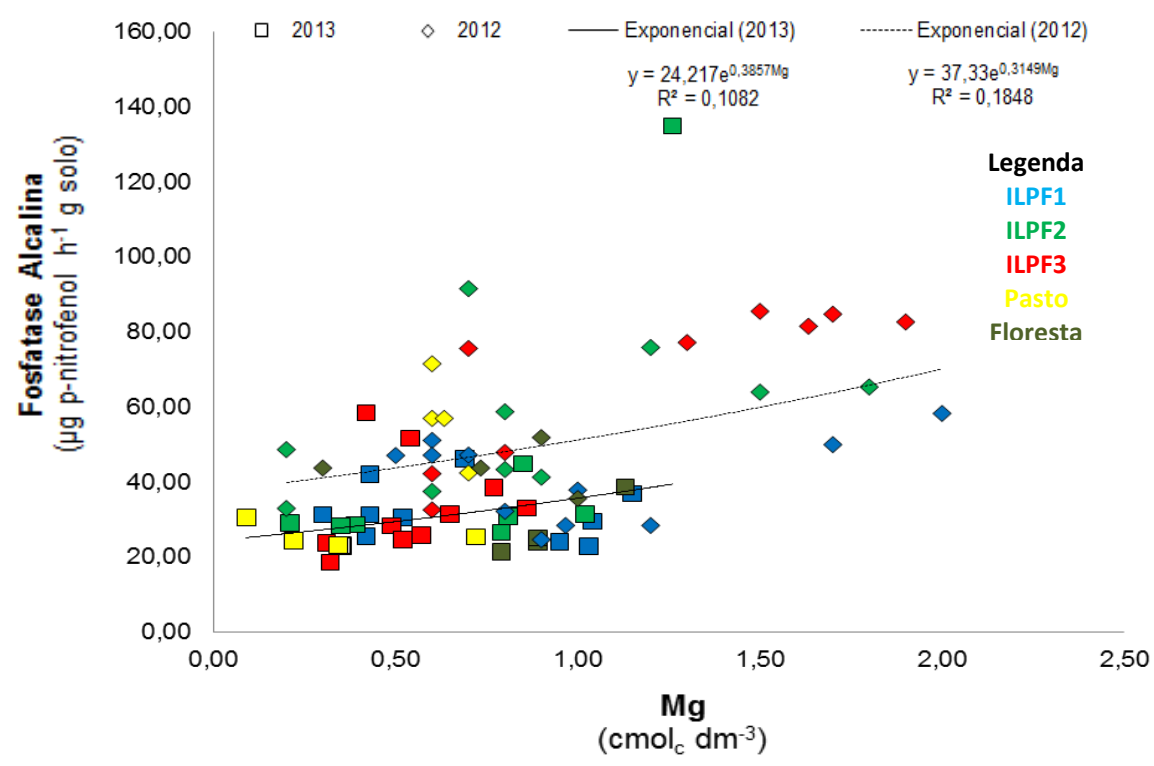

Pode inferir que o $\mathrm{Mg}$ foi proveniente da calagem realizada com calcário dolomítico, no período de preparo do solo para a safra 2011/2012. Dessa forma é explicável a presença da atividade da enzima onde houve maior concentração de $\mathrm{Mg}$. Valem observar que não houve tendência clara da atividade em algum manejo, eles apresentam dispersão das repetições em ambos os anos, com valores diferentes do produto da atividade enzimática, porém, na maioria dos casos entre os valores de 20,0 e $80,0 \mu \mathrm{g}$ p-nitrofenol $\mathrm{h}^{-1} \mathrm{~g}$ solo e com os teores de 0,0 , a $1,0 \mathrm{cmol}_{\mathrm{c}} \mathrm{Mg} \mathrm{dm}^{-3}$.

Resultados da literatura apontam que a fosfatase alcalina é mediada, inicialmente pelo $\mathrm{pH}$ do meio, seguido de compostos químicos, onde o $\mathrm{Mg}$ ocupa posto importante na sequência de afinidades do sítio ativo. Os micro-organismos têm perfis de adaptação imediata frente às alterações químicas, dessa forma ainda não sabem quais são os elementos chave para cada enzima (KANDELER; GERBER, 1988; TABATABAI, 1994; MAKOI; NDAKIDEMI, 2008).

O Mg também apresentou relação com a enzima urease. $O$ modelo linear foi o que melhor ajustou para a regressão entre urease e $\mathrm{Mg}$, para ambos os anos, porém observou relação inversa nos anos de avaliação. Para o primeiro ano (2012) a crescente dose de Mg levou a tendência de aumento da atividade da urease, e o coeficiente de determinação expressa que $18,3 \%$ da urease pode ser explicadas pelo $\mathrm{Mg}$; enquanto no segundo ano, 2013, observa o inverso, o aumento do teor de $\mathrm{Mg}$ decresceu a atividade da urease, porém o coeficiente de determinação foi de $19,5 \%$ (Figura 3 ). 
Figura 3. Comparação entre as regressões das variáveis urease em função do magnésio $(\mathrm{Mg})$ nos dois anos de avaliação, 2012 e 2013.

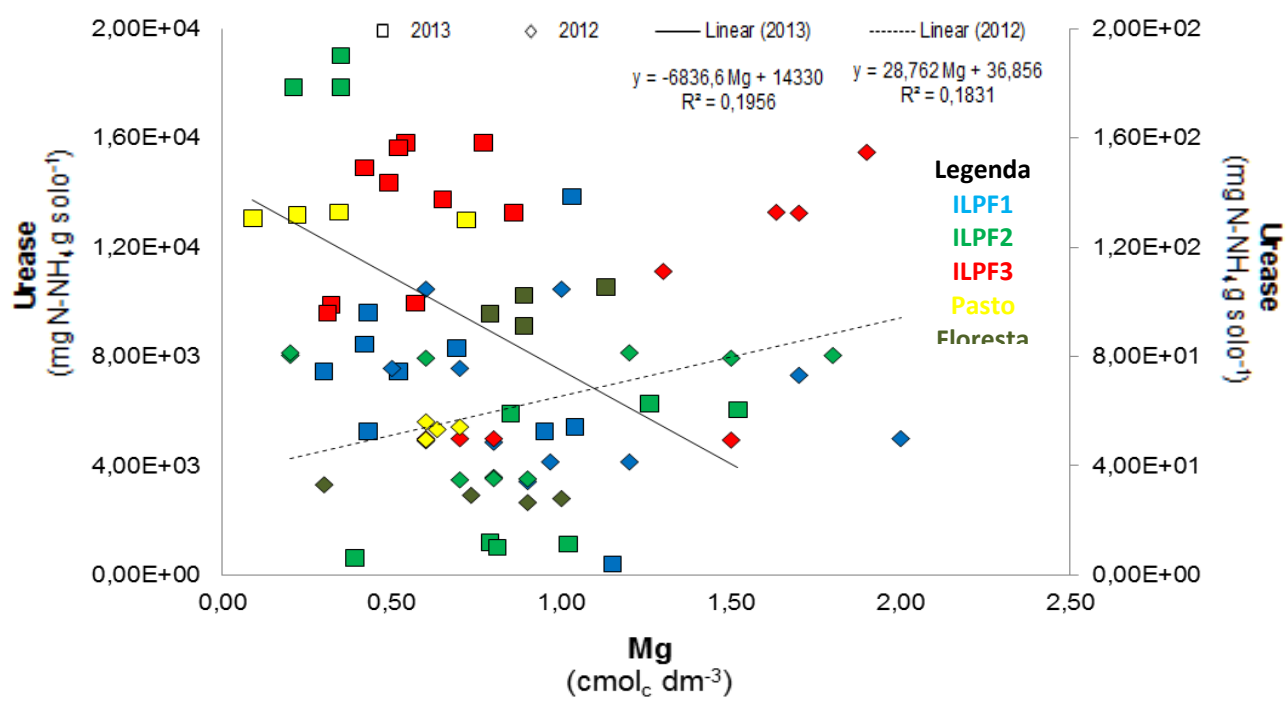

A relação inversa pode ter ocorrido de acordo com a mudança da disponibilidade da própria matéria orgânica a ser degradada, uma vez que no segundo ano de avaliação a presença de compostos ureados tendeu a ser maior pelo maior tempo de pastejo dos animais na área e, assim a adição de resíduos foi em maior quantidade.

Como já referido, a dinâmica microbiológica é passível de rápida adaptação, porém identificar possíveis interferentes que estimulam ou minimizam impactos sobre a comunidade, é uma ferramenta útil para estimular ou minimizar a ciclagem dos nutrientes nos sistemas, especialmente quando assumidos sistemas sustentáveis de produção.

\section{Conclusões}

1. A enumeração e atividade dos microorganismos do solo apresentaram maior variação em relação ao ano de coleta do que em relação ao manejo adotado;

2. A microbiota do solo nos manejos avaliados foi infuenciada principalmente pelos atributos químicos acidez potencial $(\mathrm{H}+\mathrm{Al})$, materia ogânica (M.O) e capacidade de troca de cations (CTC);

3. O magnésio (Mg) foi fator importante na atividade das enzimas fosfatase alcalina e urease;

4. Constatou-se a necessidade de maior tempo de avaliação dos sistemas para atribuição de conclusões assertivas sobre a sustentabilidade dos sistemas estudados.

\section{Referências}

ALEF, K.; NANNIPIERI, P. Methods in applied soil microbiology and biochemietry. London: Academic Press, 1995. 576p.

ALVARENGA, R. C.; VIANA, M. C. M.; GONTIJO NETO, M. M. O estado da arte da Integração Lavoura Pecuária-Floresta (ILPF) no Brasil. In: SANTOS, L. D. T.; MENDES, L. R.; DUARTE, E. R.; GLÓRIA, J. R.; ANDRADE, J. M.; CARVALHO, L. R.; SALES, N. L. P. Integração lavoura-pecuáriafloresta: potencialidades e técnicas de produção. 1. ed. Montes Claros: ICA/UFMG, 2012. p.11

AZEVEDO, C. M. B. C. de; SILVA, A. R.; ALVES, L. W. R.; FERNANDES, P. C. C.; CARVALHO, E. J. M.; VELOSO, C. A. C.; OLIVEIRA JUNIOR, M. C. M. de; SILVEIRA FILHO, A. Desempenho dos componentes agrícolas e do mogno africano (Khaya ivorensis) em sistemas de integração lavoura-pecuária-floresta no município de Terra Alta - PA. In: WORKSHOP INTEGRAÇÃO LAVOURAPECUÁRIA-FLORESTA EM RONDÔNIA, 1., 2010, Porto Velho. Anais [...]. Porto Velho: Embrapa Rondônia, 2010. p. 36-44.

BALBINO, L.C.; CORDEIRO, L.A.M.; PORFÍRIO-DA-SILVA, V.; MORAES, A.; MARTÍNEZ, G.B.; ALVARENGA, R.C.; KICHEL, A.N.; FONTANELI, R.S.; SANTOS, H.P.; FRANCHINI, J.C.; GALERANI, P.R. Evolução tecnológica e arranjos produtivos de sistemas de integração lavoura-pecuária-floresta no Brasil. Pesquisa Agropecuária Brasileira, v.46, p.i-xii, 2011. 
https://doi.org/10.1590/S0100-

\section{X2011001000001}

BAYER, C.; LOVATO, T.; DIECKOW, J.; ZANATTA, J. A.; MIELNICZUK, J. A method for estimating coefficients of soil organic matter dynamics based on long-term experiments. Soil Tillage Research, v.91,

p.217-226 2006. https://doi.org/10.1016/j.still.2005.12.006

BLAGODATSKAYA, E.; KUZYAKOV, Y. Active microorganisms in soil: Critical review of estimation criteria and approaches. Soil Biology and Biochemistry. v.67, p.192-211, 2013. https://doi.org/10.1016/j.soilbio.2013.08.024

BREMNER, J.M.; KROGMEIER, M.J. Evidence that the adverse effect of urea fertilizer on seed germination in soil is due to ammonia formed through hydrolysis of urea by soil urease. Proceedings of the National Academy of Sciences, n.86, p.8185-8188, 1989. https://doi.org/10.1073/pnas.86.21.8185

CARNEIRO, M.A.C.; SIQUEIRA, J.O.; MOREIRA, F.M.S.; SOARES, A.L.L. Carbono orgânico, nitrogênio total, biomassa e atividade microbiana do solo em duas cronosseqüências de reabilitação após a mineração de bauxita. Revista Brasileira de Ciência do Solo, v.32, n.2, p. 621632, 2008. https://doi.org/10.1590/S0100$\underline{06832008000200017}$

CHIODINI, B. M.; SILVA, A. G.; NEGREIROS, A. B.; MAGALHÃES, L. B. Matéria orgânica e a sua influência na nutrição de plantas. Cultivando o Saber, Cascavel, v. 6, n. 1, p. 181-190, 2013.

CRUZ, J. C. S.; GAVA, G. J. C.; MINHONI, M. T. A.; SOUZA, N. L.; SILVA, M. A.; JERONIMO, E. M.; PADOVANI, C. R. Modificações químicas em solo solarizado, com e sem incorporação de resíduos orgânicos. Semina, v.29, n.1, p.15-28, 2008. https://doi.org/10.5433/1679-

$\underline{0359.2008 v 29 n 1 p 15}$

EIVAZI, F.; TABATABAl, M. A. Phosphatases in soils. Soil Biology and Biochemistry, v. 9, p. 167172, 1977. https://doi.org/10.1016/00380717(77)90070-0

EKENLER, M.; TABATABAI, M. A. Effects of liming and tillage systems on microbial biomass and glycosidases in soils. Biology and Fertility of Soils, v.39,

p.51-61,

2003.

https://doi.org/10.1007/s00374-003-0664-8

EMBRAPA. Sistema brasileiro de classificação de solos. Brasília: Embrapa Serviço de Produção de Informação, 1999. 412 p.

GOMIDE, P. H. O.; SILVA, M. L. N.; SOARES, C. R. F. $S$. Atributos físicos, químicos e biológicos do solo em ambientes de voçorocas no município de Lavras-MG. Revista Brasileira de Ciência do Solo, v.35, p.567-577, 2011. https://doi.org/10.1590/S0100$\underline{06832011000200026}$

JENKINSON, D. S.; POWLSON, D. S. The effects of biocida treatment on metabolism in soil - V. Method for measuring soil biomass. Soil Biology and Biochemistry, v.8, p.209-213, 1976. https://doi.org/10.1016/0038-0717(76)90005-5

KANDELER, E.; GERBER, H. Short-term assay of soil urease activity using colorimetric determination of ammonium. Biology and Fertility of Soils, v.6, p.68-72, 1988. https://doi.org/10.1007/BF00257924

LISBOA, F.J.G; CHAER, G.M.; FERNANDES, M.F.; BERBARA, R.L.L.; MADARI, B.E. The match between microbial community structure and soil properties is modulated by land use types and sample origin within an integrated agroecosystem. Soil Biology and Biochemistry, v.78, p.97-108, 2014. https://doi.org/10.1016/i.soilbio.2014.07.017

MAKOI, J.H.J.R.; NDAKIDEMI, P.A. Selected soil enzymes: examples of theirs potential roles in the ecosystem. African Journal of Biotechnology, v.7, n.3, p.181-191, 2008.

MARTHA JR., G. B.; VILELA, L.; SOUSA, D. M. G. Cerrado: uso eficiente de corretivos e fertilizantes em pastagens. Embrapa-Cerrados, Planaltina, 2007. 224 p.

MENDES, I.C.; HUNGRIA, M.; REIS-JUNIOR, F.B. dos; FERNANDES, M.F.; CHAER, G.M.; MERCANTE, F.M.; ZILLI, J.E. Bioindicadores para avaliação da qualidade dos solos tropicais: utopia ou realidade? Planaltina: Embrapa Cerrados, 2009. 31p. (Embrapa Cerrados. Documentos, 246). 
NEVES, C.M.N.; SILVA, M.L.N.; CURI, N.; MACEDO, R.L.G.; MOREIRA, F.M.S.; D'ANDRÉA, A.F. Indicadores biológicos da qualidade do solo em sistema agrossilvopastoril no nordeste do estado de minas Gerais. Ciência e Agrotecnologia, v. 33, n.1, p.105-112, 2009. https://doi.org/10.1590/S1413-

$\underline{70542009000100015}$

PREVIATI, M.; CANONE, D.; BEVILACQUA, I.; BOETTO, G.; POGNANT, D. e FERRARIS, S. Evaluation of wood degradation for timber check dams using time domain reflectometry water content measurements. Ecological Engineering, v.44, p.259-268, 2012. https://doi.org/10.1016/i.ecoleng.2012.03. $\underline{004}$

RAMESH, S.; MATHIVANAN, N. Screening of marine actinomycetes isolated from the Bay of Bengal, India for antimicrobial activity and industrial enzymes. World Journal of Microbiology and Biotechnology, v.25, p.21032111, 2009. https://doi.org/10.1007/s11274-009$\underline{0113-4}$

REIS JUNIOR, F. B.; MENDES, I. C. Biomassa microbiana do solo. Planaltina: Embrapa Cerrados, 2007. 40p. (Documentos, 205).

RICHARDSON, A.E.; SIMPSON, R.J. Soil microorganisms mediating phosphorus availability. Plant Physiology, n.156, p.989-996, 2011. https://doi.org/10.1104/pp.111.175448

ROLIM, G.S.; CAMARGO, M.B.P.; LANIA, D.G.; MORAES, J.F.L. Classificação climática de Köppen e de Thornthwaite e sua aplicabilidade na determinação de zonas agroclimáticas para 0 estado de São Paulo. Bragantia, v. 66, n. 4, p. 711-720, 2007. https://doi.org/10.1590/S0006$\underline{87052007000400022}$

SANTOS, E.A.; FERREIRA, L.R; COSTA, M.D.; SANTOS, J.B.; SILVA, M.C.S.; ASPIAZU, I. The effects of soil fumigation on the growth and mineral nutrition of weeds and crops. Acta Scientiarum Agronomy, n. 34, p.207-212, 2012. https://doi.org/10.4025/actasciagron.v34i2.1297 $\underline{1}$

SCHUMACHER, M.V.; BRUN, E.J.; ILLANA, V.B.; DISSIUTA, S.I.; AGNE, T.L. Biomassa e nutrientes em um povoamento de Hovena dulcis Thumb., plantado na Fepagro florestas, Santa Maria, RS. Ciência Florestal, v.18, n.1, p.27-37, 2008. https://doi.org/10.5902/19805098519

SEPLAN-MT. 2014. Disponível em: http://www.zsee.seplan.mt.gov.br. Acesso em: 06 jan. 2014.

SILVEIRA, R. L. V.; MALAVOLTA, E. Nutrição e adubação potássica em Eucalyptus. Informações Agronômicas, n. 91, p. 1-12, 2000. (Encarte Técnico-Potafós)

SONDI, I.; SALOPEK-SONDI, B. Influence of the primary structure of enzymes on the formation of $\mathrm{CaCO}_{3}$ polymorphs: a comparison of plant (Canavalia ensiformis) and bacterial (Bacillus pasteurii) ureases. Langmuir, n. 21, p.88768882, 2005. https://doi.org/10.1021/la051129v

SPSS. IBM SPSS Statistics 19 Brief Guide. SPSS, 2010. 171p.

STAVI, I.; LAL, R.; JONES, S.; REEDER, R.C. Implications of cover crops for soil quality and geodiversity in a humid-temperate region in the Midwestern USA. Land Degradation and Development, n.23, p.322-330, 2012. https://doi.org/10.1002/ldr.2148

TABATABAI, M. A. Soil enzymes. In: Weaver, R.W., Angle, S., Bottomley, P. (Eds.), Methods of Soil Analysis. Part 2: Microbiological and Biochemical Properties. Soil Science Society of America, Madison, p.775-833, 1994. https://doi.org/10.2136/sssabookser5.2.c37

TABATABAI, M. A.; BREMNER, J. M. Use of $\rho$ nitrophenyl Phosphate for Assay of Soil Phosphatase Activity. Soil Biology and Biochemistry, v.1, 1969. https://doi.org/10.1016/0038-0717(69)90012-1 TOMÉ JÚNIOR., J. B. Manual para interpretação de análise de solo. Guaíba: Agropecuária, 1997.

WOLLUM, A. G. Cultural methods for soil microorganisms. In: PAGE, A. L.; MILLER, R. H.; KEENEY, D. R. Methods of soil analysis. Madison: Soil Science Society of America, 1982. p.781-802. https://doi.org/10.2134/agronmonogr9.2.2ed.c3 $\underline{7}$ 